\title{
RANCANG BANGUN SISTEM APLIKASI PENERIMAAN SISWA BARU MENGGUNAKAN METODE AGILE DI SMK MODELLINK KABUPATEN SORONG
}

\author{
Irman Amri ${ }^{1}$, Afif Praseto Aji ${ }^{2}$ \\ ${ }^{1,2}$ Fakultas Teknik Program Studi Teknik Informatika Universitas Muhammadiyah Sorong
}

Avifkillers@gmail.com

\begin{abstract}
The purpose of this study is to design: 1) Designing an Application System for New Student Adoption Using Agile Methods at SMK MODELLINK in Sorong Regency, 2) This system is expected to facilitate the School (Administration) in processing Data for New Student Candidates.

This study uses the Agile method with the stages of data collection, analysis, design / design, coding, testing, implementation, and system maintenance. This system is created using Visual Studio 2010, with visual basic programming language, and Sql Server database applications. This system can process prospective student identity data and prospective student selection, and also print data reports on new prospective students.
\end{abstract}

Keywords : Visual Studio 2010, Visual Basic, Sql Server, Agile.

\begin{abstract}
Abstrak
Tujuan dari penelitian ini yaitu untuk melakukan peancangan : 1) Rancang Bangun Sistem Aplikasi Penerimaan Siswa Baru Menggunakan Metode Agile DI SMK MODELLINK Kabupaten Sorong, 2) Sistem ini diharapkan dapat mempermudah pihak Sekolah (Tata Usaha) dalam melakukan pengolahan Data Calon Siswa Baru.

Penelitian ini menggunakan metode Agile dengan tahapan pengumpulan data, analisis, perancangan/desain, pengkodean, pengujian, implementasi, dan pemeliharaan sistem. Sistem ini dibuat menggunakan Visual Studio 2010, dengan bahasa pemrograman visual basic, dan aplikasi database Sql Server. Sistem ini dapat mengolah data identitass calon siswa dan seleksi calon siswa, dan juga mencetak laporan data calon siswa baru.
\end{abstract}

Kata Kunci : Visual Studio 2010, Visual Basic, Sql Server, Agile.

\section{Pendahuluan}

Sekolah adalah lembaga pendidikan yang memberikan pengajaran bagi peserta didik untuk mendapatkan keilmuan. Sekolah yang baik akan memperhatikan manajemen yang baik pula. Salah satu aktivitas yang mendukung proses manajemen sekolah yang baik adalah kualitas proses penerimaan siswa baru. Sistem penerimaan siswa baru diharapkan mampu memberikan seleksi terhadap calon siswa yang siap masuk menjadi siswa di suatu sekolah.

SMK Modellink Kabupaten Sorong adalah salah satu sekolah kejuruan swasta di Kabupaten Sorong yang sedang berupaya meningkatkan kualitas manajemen sekolah agar lebih baik dan kompetitif. Oleh karena itu, dalam hal seleksi calon siswa baru, tentu membutuhkan sistem handal dalam proses tersebut. Sebab SMk Modellink Kabupaten Sorong, dalam proses penerimaan calon siswa baru masih dilakukan secara manual belum memanfaatkan sebuah sistem terkomputerisasi.

\section{Kerangka Teori}

Siswa baru yang mendaftar di SMP Plus Babussalam, khususnya untuk masuk ke pesantren, mayoritas berasal dari luar kota. Proses penerimaan siswa baru (PSB) di sekolah ini yang masih menggunakan sistem konvensional, sehingga calon siswa terkadang kesulitan mendapatkan informasi untuk melakukan proses pendaftaran. Proses administrasi juga cenderung lambat, karena data belum terintegrasi dan terkelola dengan baik. Proses ini juga masih menggunakan arsip dalam bentuk fisik yang rentan mengalami kerusakan atau bahkan hilang. Untuk dapat mengatasi permasalahan yang terjadi pada pendaftaran siswa baru di SMP Plus Babussalam dibuatlah perancangan dan pembangunan aplikasi Sistem Informasi Penerimaan Siswa Baru Berbasis Web. Metode yang digunakan untuk pembangunan sistem informasi menggunakan Model Prototype dengan pendekatan sistem berorientasi objek yang dimodelkan menggunakan UML (Unified Modelling Language). Hasil akhir dari perancangan dan pembangunan sistem informasi ini adalah adanya sebuah aplikasi yang dapat memberi kemudahan akses 
informasi dan proses pendaftaran sehingga proses administrasi penerimaan siswa baru menjadi lebih efektif dan efisisen[2].

SMK Diponegoro adalah salah satu instansi sekolah tingkat SLTA yang dalam pengelolaan pendaftaran siswa baru masih menggunakan metode pencatatan manual. Dengan metode tersebut dirasa belum memenuhi standarisasi yang ditetapkan pemerintah sehingga mengurangi prestasi instansi tersebut pada saat akreditasi. Sistem informasi ini bertujuan untuk memudahkan dalam administrasi pendaftaran siswa baru yang membantu bagi panitia penerimaan siswa baru di instansi tersebut. Manfaat dari sistem ini antara lain mudah dalam melakukan pendataan dan menghasilkan laporan yang valid dan akurat. Metode yang digunakan adalah kepustakaan, observasi analisis perancangan dan pengujian program. Diharapkan dengan adanya Sistem ini dapat membantu memudahkan lembaga tersebut dalam melakukan pendataan kepada calon peserta didik barunya[3].

Diketahui bahwa sistem informasi memainkan peran penting di sekolah di Indonesia memberikan informasi yang berguna untuk kepentingan operasi dan manajemen. Karena itu, banyak sekolah yang memiliki departemen teknologi informasi atau informasi sistem. Juga, SMA KARTINI BATAM yang merupakan lembaga pendidikan yang memiliki selalu ingin mengikuti perkembangan teknologi informasi. SMA KARTINI BATAM masih menggunakan manual untuk mencatat penerimaan yang baru siswa. Oleh karena itu, dibutuhkan suatu sistem untuk mengelola data penerimaan baru. Selama ini SMA KARTINI BATAM tidak memiliki sistem yang dapat memfasilitasi karyawan untuk mengelola data penerimaan baru. Dalam proposal ini, Penulis ingin menganalisis subjek-subjek ini dan hasilnya dimaksudkan untuk memberikan saran kepada SMA KARTINI BATAM dalam memproses data siswa sistem Informasi. Selain itu, penulis juga merekomendasikan SMA KARTINI BATAM untuk mengembangkan basis data siswa untuk dimanfaatkan ize data telah disimpan dalam database[4].

Dalam bidang pendidikan selalu dibutuhkan berbagai informasi untuk menunjang proses pembelajaran. Untuk itu sangat diperlukan sistem informasi yang mampu mengelola data-data secara efektif dan efisien. Pengelolaan data terpenting dalam operasional sekolah adalah pengelolaan data kesiswaan yang dimulai sejak penerimaan siswa baru. Data-data yang diperoleh dalam tahap ini akan digunakan selama siswa menjalani pendidikan hingga lulus. Bahkan tetap digunakan hingga siswa melanjutkan ke jenjang pendidikan yang lebih tinggi. Karena itu penelitian ini akan membangun sistem informasi penerimaan calon siswa baru yang memudahkan pengelolaan data sehingga memaksimalkan kinerja penerimaan calon siswa baru pada SMPN 1 Atap Lembobelala. Penelitian ini merupakan penelitian kualitatif dengan pendekatan rekayasa perangkat lunak. Data dikumpulkan dengan teknik observasi[5].

SMK Sakti Gemolong merupakan salah satu instansi yang bergerak dibidang pendidikan membutuhkan sumber data dan pengolah data yang tepat agartercipta efisiensi dan keakuratan data yang dapat mendukung prosesoperasional, menejemendan proses pengambilan keputusan dengan baik dantepat.Proses Penerimaan Siswa Baru (PSB) di SMK Sakti Gemolong selama inisistem yang digunakan masih bersifat manual yaitu para calon siswa dalam prosesregistrasi memasukkan data dengan menulis pada formulir pendaftaran setelahdata yang ditulis pada formulir pendaftaran, baru kemudian direkap oleh panitiaPSB kedalam komputer. Karena jumlah pendaftar yang cukup banyak yaitusekitar900 pendaftar, sehingga dalam proses input dan olah data membutuhkanwaktu yang tidak sedikit.Mengatasi hal tersebut, dibuatlah suatu sistem informasi untuk mengolahdata pendaftar pada proses penerimaan siswa baru, sehingga proses input dan olahdata calon siswanantinya dapatdihasilkaninformasi yang cepat, tepat dan akuratsesuai dengan kebutuhan.Sehingga diperoleh sebuah sistem informasi pendaftaran dengan hasilyang diinginkan berupa laporan yang cepat dan akurat setelah dilakukan testingprogram dengan menggunakan jaringan client server[6].

Makalah ini menyajikan penelitian dan penemuan sistem pendaftaran siswa di MethodistUniversity College Ghana. Ditemukan bahwa siswa harus hadir secara fisik di kampus mereka untuk melakukan pendaftaran semester, setelah pembayaran biaya. Dengan banyaknya alternatif dalam pilihan teknologi, riset ini mengurutkan mencari tahu alternatif mana yang akan membantu menghilangkan kesulitan yang dialami siswa saat ini untuk mendaftar semester. Makalah ini menganalisis sistem yang ada menggunakan model air terjun yang mengarah ke desain dan pengembangan sistem pendaftaran online yang tidak memerlukan kehadiran fisik siswa di kampus tetapi untuk mendaftar dari jarak jauh[7].

Berdasarkan penelitian-penelitian yang telah dilakukan, ada perbedaan yang dibuat oleh penulis, yaitu penulis menggunakan model agile dalam menyelesaikan masalah yang ada, selain itu penulis membuat form seleksi calon siswa baru dalam sistem ini, agar siswa yang ingin mendaftar tidak melebihi kapasitas yang ada di instansi tersebut.

\subsection{Teori / Literatur Terkait}

\subsubsection{Microsoft Visual Basic 2010}

Microsoft Visual Basic 2010 adalah bahasa pemrograman event-driven yang berasal dari BASIC. Event driven artinya program menunggu sampai adanya respons dari pemakai berupa kejadian tertentu, misalnya tombol diklik atau menu dipilih. Ketika event terdeteksi, event yang berhubungan akan melakukan aksi sesuai dengan kode yang diberikan". 


\subsection{SQL Server}

\subsubsection{Pengertian SQL Server}

Menurut (Agus Saputra; 2013:11-12) Microsoft SQL Server merupakan salah satu produk RDBMS. RDBMS memilik kepanjangan Relational Database Management System. Merupakan salah satu produk andalan yang dibuat oleh Microsoft yang berfungsi sebagai reational database. Micorsoft $S Q L$ Server mendukung $S Q L$ sebagai bahasa pemroses query. Seperti yang kita ketahui, $S Q L$ merupakan bahasa standar international untuk proses query database dan $S Q L$ ini sudah banyak sekali digunakan pada hampir semua aplikasi, baik itu e-commerce, pendidikan, organisasi, pemerintah, atau bahkan personal sekali pun.

\subsection{Model Agile}

\subsubsection{Agile Software Development}

Istilah Agile sendiri terdiri dari dua pengertian, yaitu: pertama pengertian dari segi filosofi, dan kedua pengertian dari segi pedoman pengembangan perangkat lunak. Dari segi filosofi, agile mempunyai arti antara lain: mendorong demi terciptanya kepuasan pelanggan; mempercepat delivery perangkat lunak secara bertahap (incremental); tim proyek yang ramping dan mempunyai motifasi yang sangat tinggi; minimasi pekerjaan sertamenyederhanakan (birokrasi) keseluruhan proses.

\subsection{Pengertian Flowchart}

Flowchart adalah adalah suatu bagan dengan simbol-simbol tertentu yang menggambarkan urutan proses secara mendetail dan hubungan antara suatu proses (instruksi) dengan proses lainnya dalam suatu program.

\subsection{Pengertian $\mathrm{DFD}$}

Data Flow Diagram (DFD) atau Diagram Alir Data (DAD) adalah suatu diagram yang menggunakan notasi-notasi untuk menggambarkan arus dari data pada suatu sistem atau menjelaskan proses kerja suatu sistem, yang penggunaannya sangat membantu untuk memahami sistem secara logika, tersruktur dan jelas. Secara singkatnya, DFD adalah alat pemodelan untuk memodelkan alur kerja sistem.

\subsection{ERD (Entity Relationship Diagram) \\ ERD (Entity Relationship Diagram)} merupakan suatu model untuk menjelaskan hubungan antar data dalam basis data berdasarkan objek - objek dasar data yang mempunyai hubungan antar relasi. ERD untuk memodelkan struktur data dan hubungan antar data, untuk menggambarkan digunakan beberapa notasi dan simbol.

\subsection{Black Box Testing}

Black Box Testing adalah suatu pengujian yang dilakukan hanya untuk mengamati hasil dari eksekusi pada software tersebut. Pengamatan hasil ini melalui data uji dan memeriksa fungsional dari perangkat lunak itu sendiri. Jadi dapat dianalogikan seperti kita melihat suatu kotak hitam. Dimana kita hanya bisa melihat penampilan pada luarnya saja, tanpa mengetahui apa yang ada dibalik kotak hitam tersebut. Pengujian black box testing ini juga mengevaluasi hanya pada tampilan luarnya saja (interface), fungsionalnya, dan tidak melihat atau mengetahui apa yang sesungguhnya terjadi di dalam proses detilnya. Namun hanya mengetahui proses input dan output-nya saja.

\section{Metodologi}

\subsection{Tempat Dan Waktu Penelitian}

Lokasi yang dijadikan tempat penelitian yaitu SMK Modellink Kabupaten Sorong.

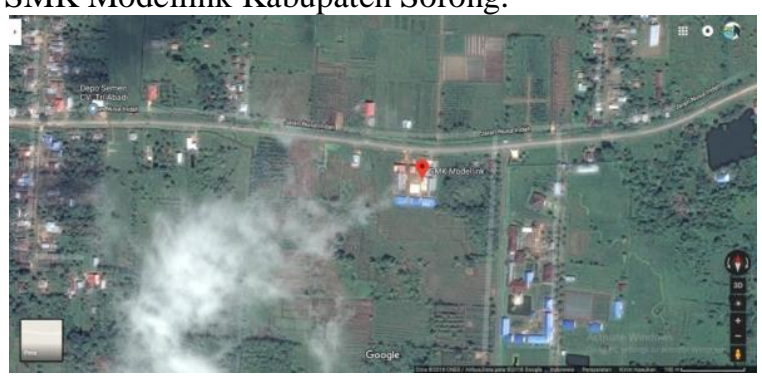

Gambar 3.1 Lokasi SMK Modellink Kabupaten Sorong

Sumber : Google Maps

\subsection{Wawancara}

Yaitu dengan cara mengadakan tanya jawab secara langsung terhadap berbagai hal yang diperlukan dengan pihak yang bersangkutan yang dipercaya untuk menjadi narasumber agar memperoleh data. Penyusunan wawancara ini adalah sebagai berikut :

Tema : Aplikasi pendaftaran siswa baru

Tujuan :Untuk mengetahui sistem pendaftaran siswa baru yang berjalan saat ini.

Sasaran :Pihak sekolah SMK Modellink Kabupaten Sorong, Bagian operator sekolah.

Waktu : Menyesuaikan dengan narasumber.

\subsection{Observasi (Survey)}

Proses pengumpulan data diperoleh dengan cara pengamatan di SMK Modellink Kabupaten Sorong secara langsung sehingga data yang diperoleh benarbenar akurat dan sesuai dengan keadaan sebenarnya.

\subsection{Studi literatur}

Studi literatur adalah salah satu metode pengumpulan data dengan cara membaca buku dan jurnal-jurnal sesuai dengan data yang di butuhkan. Pada penelitian ini penulis memilih studi literatur untuk mengumpulkan referensi dari jurnal-jurnal yang memiliki kemiripan dengan judul.

\section{Hasil dan Pembahasan}




\subsection{DFD (Data Flow Diagram)}

\subsubsection{External Entity}

External Entity yang menggunakan sistem aplikasi penerimaan siswa baru pada SMK Modellink Kabupaten Sorong dapat dilihat pada Tabel 4.1

Tabel 4.1 External Entity dalam sistem aplikasi penerimaan siswa baru

\begin{tabular}{|c|c|l|}
\hline No & $\begin{array}{l}\text { EXTERNAL } \\
\text { ENTITY }\end{array}$ & \multicolumn{1}{|c|}{ DESKRIPSI } \\
\hline 1 & Admin & $\begin{array}{l}\text { Pihak yang memiliki semua } \\
\text { akses pada sistem. }\end{array}$ \\
\hline 2 & $\begin{array}{l}\text { Pihak yang berhak } \\
\text { Kenerima informasi } \\
\text { Sekolah } \\
\text { berupa laporan laporan } \\
\text { data siswa pendaftar, } \\
\text { laporan siswa peserta tes, } \\
\text { dan laporan siswa ikut tes. }\end{array}$ \\
\hline
\end{tabular}

\subsection{Implementasi}

\subsubsection{Implementasi Basis Data}

Implementasi basis data dibuat menggunakan diagram ERD (Entity Relationship Diagram) dan digunakan untuk menyimpan setiap data yang akan diinputkan pada Sistem aplikasi penerimaan siswa baru. Setiap tabel memiliki salah satu field unik yang disebut primary key. Setiap data memiliki tipe data yang sudah ditentukan.

\subsection{Implementasi User Interface}

Implementasi user interface merupakan tampilan menu - menu yang ada pada Aplikasi penerimaan siswa baru.

\subsubsection{Tampilan Halaman Login}

Halaman login merupakan halaman yang digunakan admin untuk masuk ke dalam sistem.

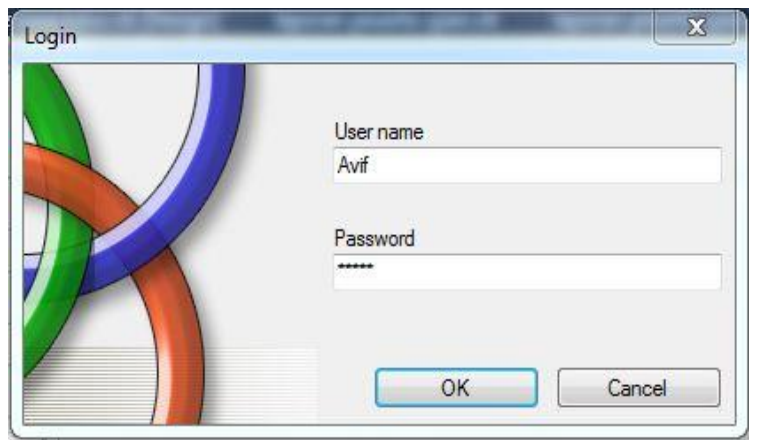

Gambar 4.1 Tampilan Halaman Login

\subsubsection{Tampilan Halaman Menu Utama}

Halaman Menu Utama merupakan halaman yang tampil setelah admin berhasil login ke dalam sistem.

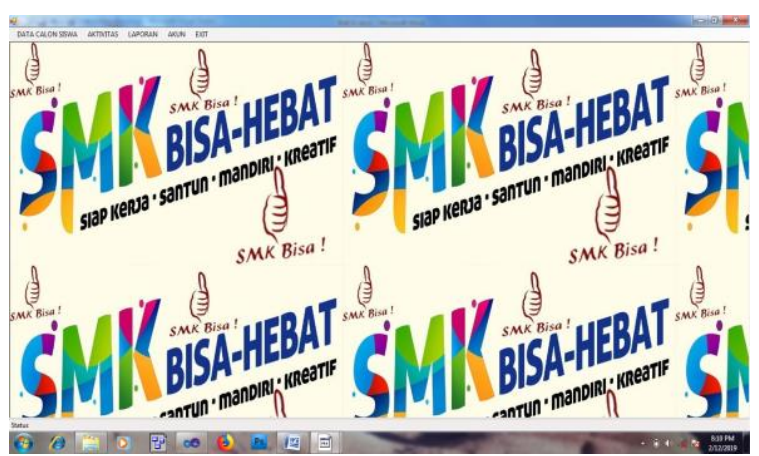

Gambar 4.2 Tampilan Halaman Menu Utama

\subsubsection{Tampilan Halaman Identitas calon siswa}

Halaman untuk menambahkan, mengubah, atau menghapus data identitas calon siswa. Pada halaman ini terdapat tabel identitas calon siswa.

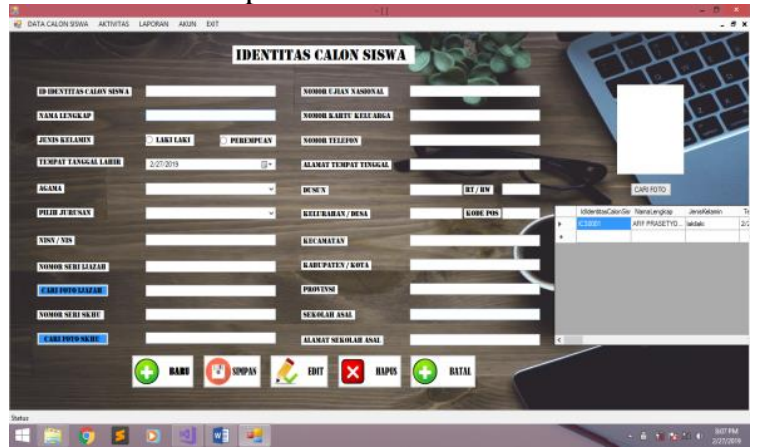

Gambar 4.3 Tampilan Halaman Identitas calon siswa

\subsubsection{Tampilan Halaman ayah kandung}

Halaman ayah kandung merupakan halaman untuk menambahkan, mengubah, atau menghapus data ayah kandung yang ada pada sekolah. Pada halaman ini terdapat tabel ayah kandung.

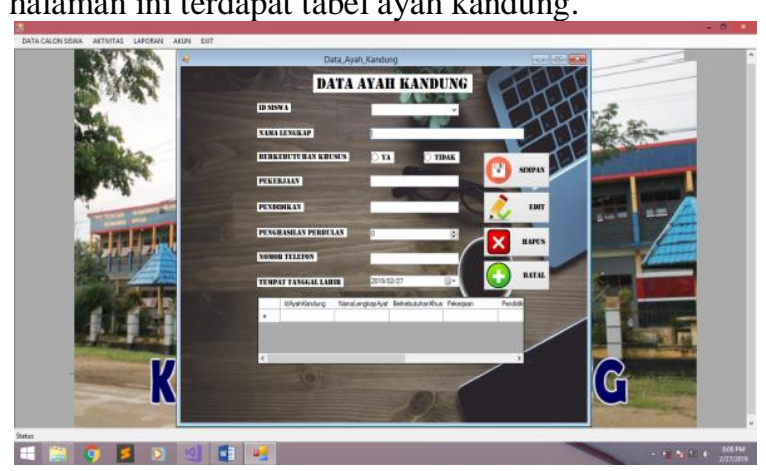

Gambar 4.4 Tampilan Halaman Ayah kandung

\subsubsection{Tampilan Halaman Ibu kandung}

Halaman ibu kandung merupakan halaman untuk menambahkan, mengubah, atau menghapus data ibu kandung yang ada di sekolah. Pada halaman ini terdapat tabel ibu kandung. 


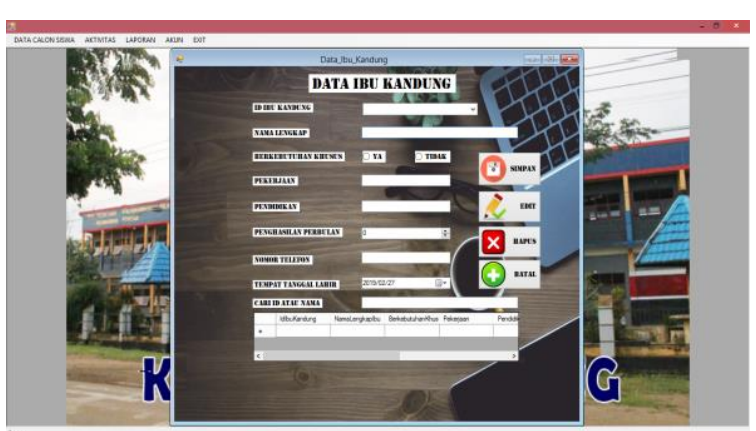

Gambar 4.5 Tampilan Halaman Ibu kandung

\subsubsection{Tampilan Halaman Wali}

Halaman Wali adalah halaman untuk menambahkan, mengubah, atau menghapus data wali yang ada di sekolah. Pada halaman ini terdapat tabel wali.

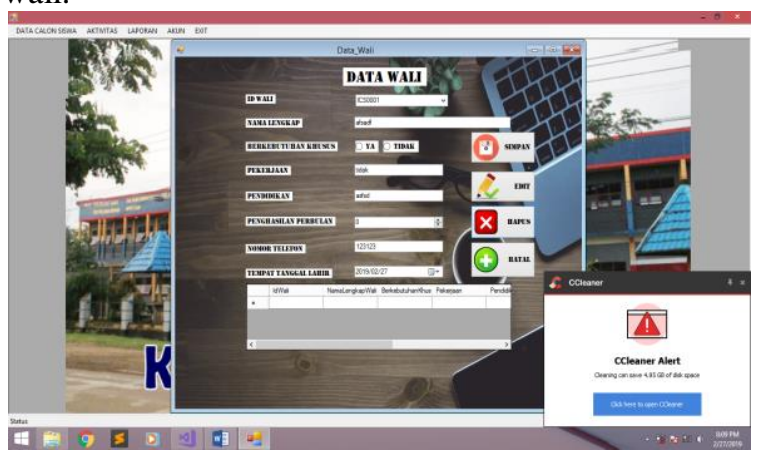

Gambar 4.6 Tampilan Halaman Wali

\subsubsection{Tampilan Halaman Data Periodik}

Halaman Periodik merupakan halaman untuk menambahkan, mengubah, atau menghapus data periodik melengkapi data identitas calon siswa. Pada halaman ini terdapat tabel periodik dengan data yang telah diinputkan.

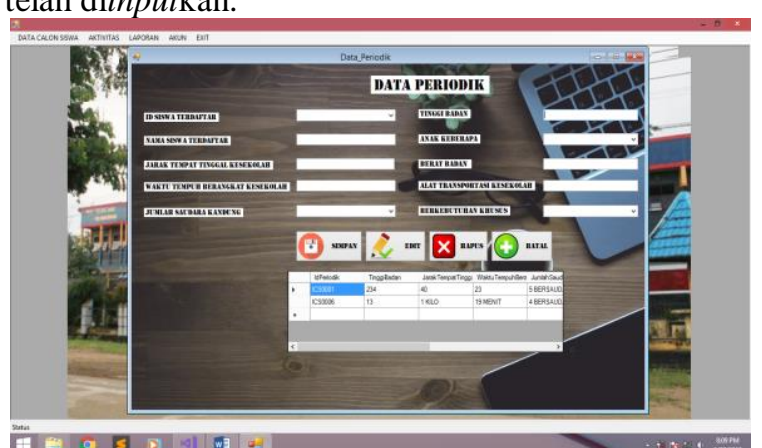

Gambar 4.7 Tampilan Halaman Data Periodik

\subsubsection{Tampilan Halaman Seleksi}

Halaman Seleksi merupakan halaman untuk menambahkan, mengubah, atau menghapus data Seleksi. Pada halaman ini terdapat tabel seleksi dengan data yang telah diinputkan.

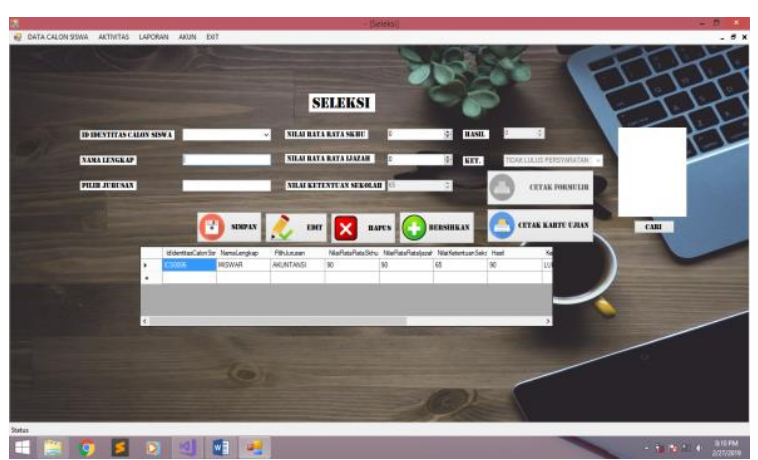

Gambar 4.8 Tampilan Halaman Seleksi

\subsubsection{Tampilan Halaman Data Ruangan}

Halaman Ruanagan merupakan halaman untuk menambahkan, mengubah, atau menghapus data ruangan. Pada halaman ini terdapat tabel ruanagan dengan data yang telah diinputkan.

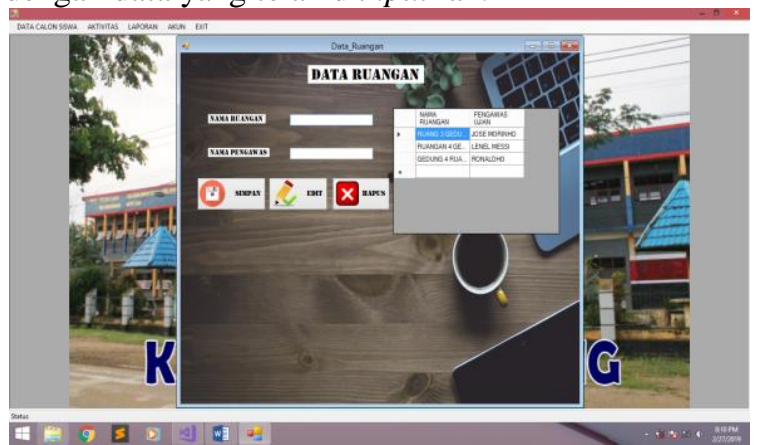

Gambar 4.9 Tampilan Halaman Data Ruangan

\subsubsection{Tampilan Halaman Akun}

Halaman untuk menambahkan, mengubah, atau menghapus data akun. Halaman ini digunakan untuk menambahkan pengguna baru atau menghapus id dan password pengguna yang sudah tidak bekerja lagi sebagai Tata usaha sekolah.

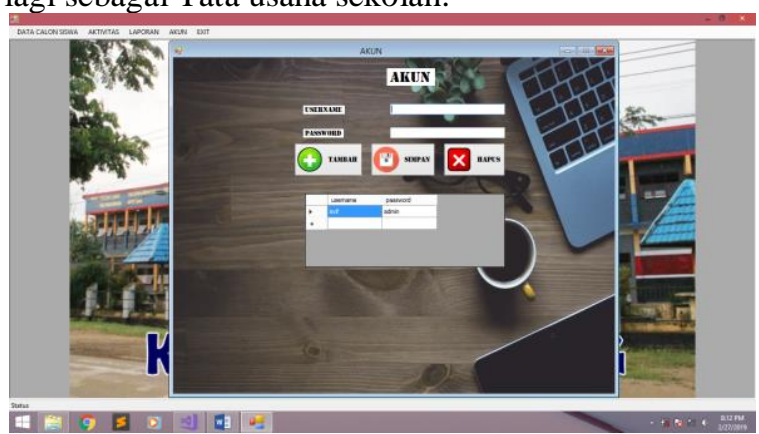

Gambar 4.10 Tampilan Halaman Akun

\subsubsection{Tampilan Halaman Laporan Data Siswa Pendaftar}

Halaman ini menampilkan hasil dari laporan siswa yang mendaftar yang akan dicetak. 


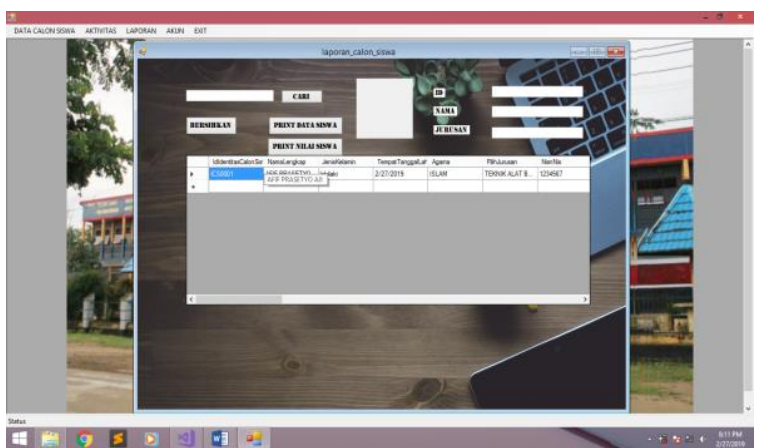

Gambar 4.11 Tampilan Halaman Siswa Yang Mendaftar

\subsubsection{Tampilan Halaman Laporan Data Siswa} Peserta Tes

Halaman ini menampilkan hasil laporan Data

Siswa Peserta Tes yang akan di cetak.

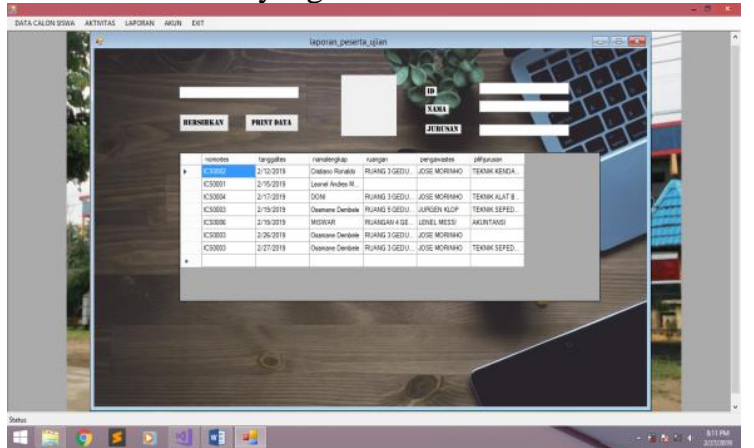

Gambar 4.12 Tampilan Halaman Laporan Peserta tes

\subsubsection{Tampilan Halaman Laporan Data Siswa} Lulus Seleksi

Halaman ini menampilkan laporan Data Siswa Lulus Tes yang akan dicetak.

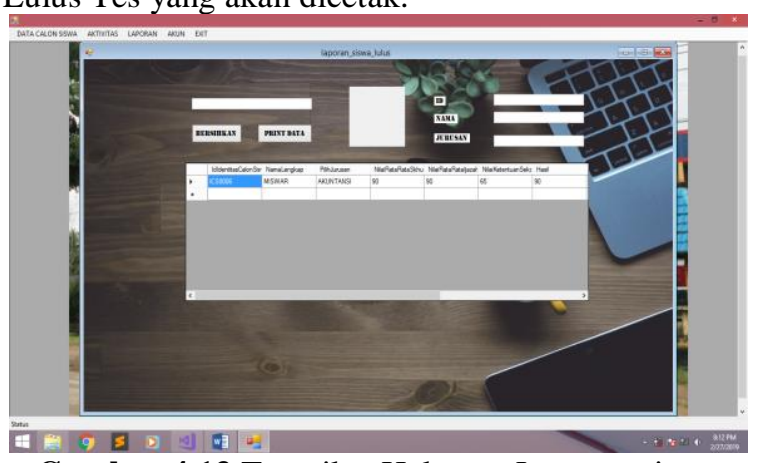

Gambar 4.13 Tampilan Halaman Laporan siswa yang lulus tes.

\subsection{Pengujian}

Pengujian sistem dilakukan untuk mengetahui apakah terdapat masalah atau error pada sistem. Pengujian dilakukan dengan menggunakan metode Black Box Testing yaitu pengujian fungsi - fungsi yang ada pada sistem. Hardware yang digunakan untuk pengujian yaitu komputer sebagai perangkat untuk mengakses sistem

\section{Kesimpulan dan saran}

\section{$5.1 \quad$ Kesimpulan}

Berdasarkan penelitian yang telah dilakukan maka penulis mengambil kesimpulan sebagai berikut, yaitu :

5.1.1 Rancang bangun sistem aplikasi penerimaan siswa baru menggunakan metode agile sudah berjalan dengan baik. Sudah dapat menampilkan semua form, diantaranya login, identitas calon siswa, data ayah kandung, data ibu kandung, data wali, data periodik, seleksi, tes masuk, dan form akun.

5.1.2 Sudah dapat menampilkan laporan, yaitu laporan data siswa pendaftar, laporan siswa tes, laporan siswa lulus tes.

5.1.3 Dapat menginputkan data identitas calon siswa dan seleksi siswa secara efektif dan efisien.

\subsection{Saran}

Berdasarkan penelitian yang telah dilakukan maka penulis meyertakan saran untuk pengembangan dari sistem ini, yaitu :

5.2.1 Penambahan fitur pembuatan jadwal mengajar guru dan jadwal belajar siswa, untuk memudahkan bagian tata usaha untuk pengolahan data lebih lanjut.

\section{Ucapan Terima Kasih}

Bismillahirrahmnirrahim.

Assalamualaikum $\mathrm{Wr}$. Wb.

Puji sukur dipanjatkan kepada Allah subhanahu wa ta'ala sehingga tugas akhir ini dapat di selesaikan. Tugas akhir ini di ajukan untuk memenuhi salah satu persyaratan memperoleh derajat kesarjanaan sastra-1 pada program studi teknik informatika universitas muhammadiyah sorong. Tugas akhir ini di beri judul Rancang Bangun Sistem Aplikasi Penerimaan Siswa Baru Menggunakan Metode Agile Di SMK Modellink Kabupaten Sorong.

Penyusun mengucapkan terima kasih kepada semuah pihak yang telah membantu dalam menyelesaikan tugas akhir ini. Ucapan tersebut di ajukan kepada:

1. Kedua orang tua penulis, Bapak Darnuji dan Ibunda Sumarni yang dengan tulus dan penuh kasih sayang dan kesabaran yang tiada batas memberikan kepercayaan, semangat, dukungan materil serta do'a yang tidak pernah putus sehingga penulis dapat menyelesaikan laporan Tugas Akhir.

2. Bapak Dr. H. Hermanto Suaib, MM. Selaku rektor Universitas Muhammadiyah Sorong.

3. Bapak Irman Amri, ST., M.T selaku Dekan Fakultas Teknik Universitas Muhammadiyah Sorong.

4. Bapak Rendra Soekarta, S.Kom., M.T selaku Ketua Program Studi Teknik Informatika Universitas Muhammadiyah Sorong.

5. Bapak Rendra Soekarta, S.Kom. M.MT. sebagai Dosen Pembimbing I dan Ibu Ery Murniyasih, S.Kom., sebagai dosen pembimbing II yang 
telah bersedia meluangkan waktu untuk membimbing dan memberi arahan sehingga penulis mampu menyelesaikan penelitian ini.

6. Ibu Luluk Suryani, S.Kom., M.Kom. selaku Dosen yang turut membantu memberikan motivasi kepada penulis.

7. Bapak/ibu Dosen dan seluruh staff Fakultas Teknik Universitas Muhammadiyah Sorong.

8. Bapak Wawan selaku Operator Sekolah yang membimbing proses kegiatan dalam pembuatan Aplikasi Penerimaan Siswa Baru Di SMK MODELLINK Kabupaten Sorong.

9. Sahabat penulis Linda Diana Putri, Rifana Rumakei, Puspita Dewi Ramadhan, yang telah memberikan semangat dan do'a kepada penulis.

10. Rekan Mahasiswa/i Teknik Informatika Angkatan 2014 yang telah memberikan dukungan dan motivasi kepada penulis.

Penulis menyadari bahwa apa yang tertulis dalam Tugas Akhir ini masih jauh dari kesempurnaan, suatu kebangaan bagi penulis apabila ada kritik dan saran yang ditujukan kepada penulis. Semoga skripsi ini dapat bermanfaat bagi seluruh pembaca. Semoga Allah SWT. Senantiasa melimpahkan rahmat dan hidayah-Nya kepada kita semua, Amin $Y a$ Robbal'Alamin.

Wassalamu'alaikum warahmatullahi wabarakatuh

\section{Daftar Pustaka}

Ahmat, K., Moch, L., Ika, P., Syaifudin, A., \& Mohamad, K. (2014). Aplikasi Penerimaan Mahasiswa Baru Universitas Yudharta Pasuruan. Fakultas Tehknik Studi Teknik Informatika Universitas Tudharta Pasuruan, $1-35$.

Arif , Y., Hariandi, M., \& Ai, R. (2012). Rancang Bangun Sistem Informasi Penerimaan Siswa Baru SD Setiamanah Mandiri I Berbasis VBNET. Arif Yulianto on Mar 05, 2014, 1-6.

Arif, W. (2016). Pengertian Use Case. Apr 1, 2016.

Arifianto, R. (2014). Pengertian Flowchart. November 20, 2014.

Aziz, M. H. (2014). Pengertian Visual Basic. September 14, 2014.

Dewi, K., \& Yestin, W. (2016). Sistem Informasi Penerimaan Calon Siswa Baru Pada SMP Negeri I Atap Lembobela Di Kabupaten Morowali. No.1 Januari-Juni 2016, 1-12.

Feronika, W. (2016). Program Aplikasi Penerimaan Siswa Baru Dengan Menggunakan Visual Basic 6.0. (STMIK) Pranata Indonesia, 7-9.

Irman, A., Achmad, R., Hendrik, P., Edwin P., M., \& Rendra, S. (2014). Pedoman Penulisan Tugas Akhir Bagi Mahasiswa Fakultas Teknik. Universitas Muhammadiyah Sorong, 1-62.

Jusmiran. (2012). Pengertian SQL Server. 14 November 2012.

Meily, S. O. (2016). Pengertian DFD. 1 Oktober 2016.
Naykala, D., \& Kalla , N. (t.thn.). Pengertian Metode Agile. Februari 09 .

Santoso. (2014). Sistem Informasi Pendaftaran Siswa Baru Pada SMK Diponegoro Tulakan. Speed Journal - Sentra Penelitian Engineering dan Edukasi - Volume 11 No 1 - Februari 2014 ijns.org , 1-7.

Saputra, W. (2012). Perancangan Sistem Informasi Pendaftaran Siswa Baru Pada SMA Kartini Batam. Sekolah Tinggi Manajemen Informatika dan Komputer AMIKOM Yogyakarta, 1-20. 